\title{
The LEW.1AR1/Ztm-iddm rat: a new model of spontaneous insulin-dependent diabetes mellitus
}

\author{
S. Lenzen ${ }^{1}$, M. Tiedge ${ }^{1}$, M.Elsner ${ }^{1}$, S. Lortz ${ }^{1}$, H.Weiss ${ }^{1}$, A.Jörns ${ }^{2}$, G. Klöppel ${ }^{3}$, D. Wedekind ${ }^{4}$, C.-M.Prokop ${ }^{4}$, \\ H.J.Hedrich ${ }^{4}$ \\ ${ }^{1}$ Institute of Clinical Biochemistry, Hannover Medical School, Hannover, Germany \\ ${ }^{2}$ Centre of Anatomy, Hannover Medical School, Hannover, Germany \\ ${ }^{3}$ Institute of Pathology, University of Kiel, Kiel, Germany \\ ${ }^{4}$ Institute for Laboratory Animal Science, Hannover Medical School, Hannover, Germany
}

\section{Abstract}

Aims/hypothesis. We describe a new Type I (insulindependent) diabetes mellitus rat model (LEW.1AR1/ $\mathrm{Ztm}-i d d m$ ) which arose through a spontaneous mutation in a congenic Lewis rat strain with a defined MHC haplotype (RT1. $\left.A^{a} B / D^{u} C^{u}\right)$.

Methods. The development of diabetes was characterised using biochemical, immunological and morphological methods.

Results. Diabetes appeared in the rats with an incidence of $20 \%$ without major sex preference at $58 \pm 2$ days. The disease was characterised by hyperglycaemia, glycosuria, ketonuria and polyuria. In peripheral blood, the proportion of $\mathrm{T}$ lymphocytes was in the normal range expressing the RT6.1 differentiation antigen. Islets were heavily infiltrated with $B$ and T lymphocytes, macrophages and NK cells with beta cells rapidly destroyed through apoptosis in areas of insulitis.

Conclusion/interpretation. This Type I diabetic rat develops a spontaneous insulin-dependent autoimmune diabetes through beta cell apoptosis. It could prove to be a valuable new animal model for clarifying the mechanisms involved in the development of autoimmune diabetes. [Diabetologia (2001) 44: 1189-1196]

Keywords Type I diabetes mellitus, animal model, rat, apoptosis.
Human Type I (insulin-dependent) diabetes mellitus results from $\mathrm{T}$ cell-mediated, autoimmune destruction of pancreatic beta cells [1-6]. Rodent models with a spontaneous development of Type I diabetes share many of the features of human Type I diabetes [7] and have therefore helped clarify aetiological and pathophysiological aspects of autoimmune diabetes $[2,8,9]$. But none of these models represents all aspects of the human disease $[2,9,10]$. Diabetes in the Biobreeding $(\mathrm{BB})$ rat $[2,3,10]$ is characterised by a

Received: 6 December 2000 and in revised form: 28 May 2001

Corresponding author: Prof. S. Lenzen, Institute of Clinical Biochemistry, Hannover Medical School, D-30623 Hannover, Germany

Abbreviations: Con A, concanavalin A; BB rat, Biobreeding rat; LETL, rat Long-Evans Tokushima lean rat; NOD, mouse non-obese diabetic mouse; Poly IC, polyinosinic-polycytidylic acid; TUNEL, TdT-mediated dUTP-X-nick end labelling genetically determined constitutive lymphopenia with absence of the RT6.1 subset of peripheral T cells $[11,12]$. In the non-obese diabetic (NOD) mouse, female mice predominantly show overt diabetes, while mice of both sexes show insulitis with infiltration of the pancreatic islets $[8,13,14]$.

Here we describe a new Type I diabetic rat model, the IDDM rat, which arose spontaneously in a defined inbred background (LEW.1AR1/Ztm) and which could provide new insights into the mechanisms underlying the development of autoimmune diabetes.

\section{Materials and methods}

Animals. LEW.1AR1/Ztm-iddm rats originated in a MHC congenic LEW.1AR1 strain (intra MHC recombination of $a$ and $u$ haplotype) in the Institute for Laboratory Animal Science of Hannover Medical School (Ztm) [15]. This LEW.1AR1 strain does not differ from LEW except for the MHC locus $\left(R T 1^{l}\right)$. 
The strain is characterised by the following marker genes: pigmentation: $a a B B$ cc hh PP RR; MHC: RT1 ${ }^{r 2}\left(R T 1 . A^{a} B / D^{u}\right.$ $\left.C^{u}\right)$; erythrocyte antigens: $R T 2^{a}, R T 8^{b}$; lymphocyte antigens: $R T 6^{a}, R T 7^{a}$; biochemical markers: Acon1 ${ }^{b}, E s 1^{a}, E s 10^{b}, F h^{a}$, Mup1 $^{b}, A c p 2^{a}, E s 2^{d}, E s 12^{a}, G c^{a}, P e p 3^{b}, E s 3^{a}, G d c 1^{a}, P g d^{b}$, Ahd2 ${ }^{c}, E s 4^{b}, E s 14^{b}$, Glo1 $^{a}, P g 1^{a}, A k p 1^{a}, E s 6^{a}, E s 15^{b}, P k 1^{b}$, $A l p 1^{b}, E s 7^{b}, E s 14^{b}, H b b^{b}, S v p 1^{b}, A m y 1^{a}, E s 8^{a}, E s 18^{a}, L_{a p 1}{ }^{b}$, $X d h 1^{b}, E s 9^{c}, M g d^{b}$ [16]. All strains in our facility are regularly submitted to a genetic monitoring programme in order to exclude the possibility of genetic contamination and to verify the authenticity of the strains [17]. The diabetic syndrome became apparent in the colony during breeding in a barrier sustained facility. Since the discovery of the mutation in Fx +13 of the LEW.1AR1 strain, the mutation has been maintained as a separate strain, originating from a single breeding cage (no. 17) in a separate, minimal, barrier sustained facility which is regularly monitored for murine pathogens according to the GV-SOLAS recommendations [18]. The rats were typed for, and shown to be antibody free from, Hanta, Kilham rat, PVM, Reo 3, Sendai, SDA, rat corona, Theiler's encephalomyelitis, and Toolan's (H1) viruses. The colony is maintained through mating of phenotypically inapparent i.e. non-diabetic female and diabetic (blood glucose 10-20 mmol/l) male LEW.1AR1/Ztm-iddm rats. All rats, both healthy and diabetic, were kept under identical conditions in groups under a 12:12 h light-dark cycle in type III Macrolon cages with free access to a sterilised standard laboratory chow (diet No. 1324, Altromin, Lippe, Germany) and water. We used both diabetic and nondiabetic LEW.1AR1-iddm rats of either sex as well as non-diabetic LEW.1AR1 genetic background control rats in this study. Continuous monitoring of the progenitor colony, LEW.1AR1, over a period of at least six generations showed that none of the descendants ever developed diabetes.

Blood and tissues. The glucose concentration in blood from the tail vein was determined with the glucose oxidase method using the Glucometer Elite (Bayer, Leverkusen, Germany). Glucose and ketone bodies in the urine were also measured enzymatically. Serum insulin was determined by a rat insulin microplate ELISA (Mercodia, Upsala, Sweden) using rat insulin as a standard. On the day when rats were killed, blood was collected as well as tissue samples for a histological examination of pancreas and other organs.

Autoantibodies. Autoantibodies to glutamate decarboxylase (GAD65) and protein-tyrosine-phosphatase (IA2) (cytoplasmic domain) were measured by radioimmunoassay and autoantibodies to cytoplasmic islet cell antibodies (ICAs) by direct immunofluorescence detection [19].

Flow cytometry. To determine the different lymphocyte subpopulations in peripheral blood cells, FACS analyses were done using the following labelled monoclonal antibodies: FITC anti rat CD45RA, FITC anti rat NKR-P1A, PE anti rat CD8 a, FITC anti rat CD4, PE anti rat CD3, FITC anti rat $\alpha \beta$ TcR (PharMingen, Hamburg, Germany), FITC anti rat RT6.1 (kindly provided by Dr. K. Wonigeit, Hannover, Germany). In a FACS tube erythrocytes from $70 \mu \mathrm{l}$ blood were lysed 2-3 times in $2 \mathrm{ml}$ lysis buffer $\left(160 \mathrm{mmol} \mathrm{NH}_{4}, 0.1 \mathrm{mmol}\right.$ EDTA, $\left.12 \mathrm{mmol} \mathrm{NaHCO}_{3}\right)$ and centrifuged $(200 \cdot \mathrm{g})$ for $3 \mathrm{~min}$ each. Thereafter the cell pellet was washed twice with FACS buffer (phosphate buffered saline, $0.03 \%$ sodium azide, $0.1 \%$ bovine serum albumin) and centrifuged again. The pellet was resuspended in $20 \mu \mathrm{l}$ pre-diluted antibody solution and incubated for $20 \mathrm{~min}$ at room temperature. After washing the cells twice with $2 \mathrm{ml}$ FACS buffer the cell pellet was resuspended in $200 \mu \mathrm{l}$ FACS buffer and measured in a flow cytometer (Model
FACSCalibur, Becton Dickinson, Franklin Lakes, N.J., USA) [20].

Morphology. For light microscopy, tissue specimens were fixed in Bouin's solution or rapidly frozen in liquid nitrogen [21]. Fixed tissue was embedded in paraffin and frozen tissue stored at $-70^{\circ} \mathrm{C}$ for cryostat histology. For electron microscopy, small pancreatic tissue specimens were fixed in $2 \%$ para-formaldehyde and $2 \%$ glutaraldehyde in $0.1 \mathrm{~mol} / \mathrm{l}$ cacodylate buffer, $\mathrm{pH} 7.3$, postfixed in $1 \% \mathrm{OsO}_{4}$ and finally embedded in Epon. Thin sections were contrast-stained with saturated solutions of lead citrate and uranyl acetate and viewed in an electron microscope [21].

Serial paraffin and cryostat sections were immunostained by the avidin-biotin-complex (ABC) method [22]. Antibodies against insulin and glucagon or against $\mathrm{B}$ and $\mathrm{T}$ lymphocytes were used on paraffin sections and monoclonal antibodies against $\mathrm{CD}^{+}$and $\mathrm{CD}^{+}$lymphocytes (Serotec, Oxford, England), macrophages (reactive with Ki-M2R) and NK cells (kindly provided by Dr. F. Fändrich, Kiel, Germany) on cryostat sections [23]. Thin sections were immunostained by the immunogold technique using insulin antibody and gold labelled anti-rabbit IgG.

Apoptotic cells in paraffin sections were stained by terminal deoxynucleotidyl transferase (TdT)-mediated end labelling of nicked DNA ends by dUTP-biotin (TUNEL method) using the In Situ Cell Death Detection Kit (Roche Diagnostics, Mannheim, Germany). Positively stained nuclei were expressed as a percentage of the total number of nuclei from all islet cells. The extension of the islets was identified by immunocytochemical staining of the islet cells in sequential sections with insulin and glucagon antibodies. Ultrastructurally apoptotic cells were identified with the electron microscope EM 9 (Zeiss, Oberkochen, Germany).

Adoptive transfer of diabetes. Lymphocytes were collected from lymph nodes and spleen of diabetic LEW.1AR1-iddm rats and taken into culture (RPMI-1640 medium supplemented with $10 \mathrm{mmol} / \mathrm{l} \mathrm{HEPES}, 2 \mathrm{mmol} / \mathrm{l}$ glutamine, $10 \mu \mathrm{mol} / 1 \mathrm{mer}-$ captoethanol and $5 \%$ fetal calf serum; GIBCO Life Technologies, Gaithersburg, Md., USA) in the presence of $5 \mu \mathrm{g} / \mathrm{ml}$ Con A (Biochrom, Berlin, Germany) for 3 days at $37^{\circ} \mathrm{C}$ in a $5 \%$ $\mathrm{CO}_{2}$ atmosphere. Then 5 to $7 \cdot 10^{6} \mathrm{Con} \mathrm{A}$-activated cells were injected before manifestation of the disease into the tail vein of non-diabetic LEW.1AR1-iddm or LEW.1AR1 non-diabetic control rats at the age of 29-35 days, which had been treated with Poly IC (Sigma, St. Louis, Mo., USA) $(7.5 \mu \mathrm{g} / \mathrm{g}$ body weight intraperitoneally) for 5 consecutive days before this transfer [24]. Blood glucose concentrations were measured three times each week thereafter for three months.

\section{Results}

In early 1997 a new diabetic rat mutant (iddm) arose spontaneously in a defined inbred congenic rat colony (LEW.1AR1) [15] maintained at the Institute for Laboratory Animal Science of Hannover Medical School. Altogether 51 out of 260 rats in this colony developed diabetes, an incidence of $20 \%$. The incidence of diabetes in the group of the male diabetic rats was $18 \%$ and $22 \%$ in the female group. All data originate from this panel of diabetic rats born in 1997 and 1998. The mean blood glucose concentra- 


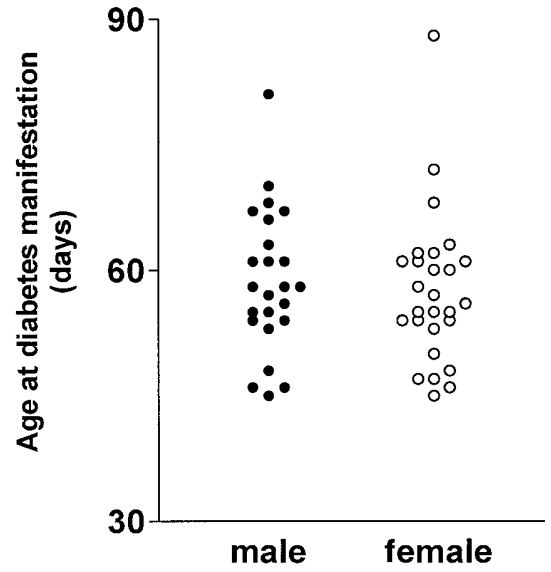

Fig. 1. Age distribution at the time of diabetes manifestation in LEW.1AR1/Ztm-iddm rats

tion at the time when these diabetic rats were killed was $18.5 \pm 0.8 \mathrm{mmol} / \mathrm{l}(n=51)$ compared with $5.8 \pm$ $0.2 \mathrm{mmol} / \mathrm{l}(n=12)$ in a group of control rats. The mean age of the rats at diabetes manifestation (blood glucose concentration in the fed state $>7 \mathrm{mmol} / \mathrm{l}$ ) was $58 \pm 2$ days $(n=51)$, being identical in males and females. Diabetes was diagnosed between 6 and 12 weeks of age with the majority at 7-9 weeks (Fig.1). None of the rats developed diabetes after 12 weeks of age.

Clinically the disease was characterised by hyperglycaemia, glycosuria, ketonuria, and polyuria. The time course of the diabetic syndrome is shown in Figure 2. On day one of diabetes manifestation, there was a steep increase in the blood glucose concentration from $6.0 \pm 0.2 \mathrm{mmol} / \mathrm{l}$ to $15.7 \pm 1.6 \mathrm{mmol} / \mathrm{l}$, increasing to $20 \mathrm{mmol} / \mathrm{l}$ within the next two days (Fig. 2). There was also a parallel, steep increase at day one of diabetes manifestation in the urine glucose concentration and the urine volume with maximal values achieved after three to five days (Fig. 2). Polydipsia (not shown) increased in parallel with polyuria (Fig. 2). Ketone bodies in the urine increased only after three days and reached a maximum on day 5 of diabetes manifestation (Fig. 2). After one week of diabetes the mean body weight of the animals had decreased $(p<0.05)$ from $214 \pm 15 \mathrm{~g}$ to $180 \pm 16 \mathrm{~g}$.

The plasma insulin concentration decreased in parallel with the increase of the blood glucose concentration as evident from a $(p<0.01)$ correlation between development of hyperglycaemia and hypoinsulinaemia (Fig. 3A).

Autoantibodies to glutamate decarboxylase (GAD65), protein-tyrosine-phosphatase (IA2) (cytoplasmic domain) and to cytoplasmic islet cell antibodies (ICA) were not detected in the sera of diabetic $(n=18)$ or of control $(n=12)$ rats.

An analysis of the lymphocyte subsets in peripheral blood of the diabetic rats showed that the proportions of T lymphocytes including the RT6.1 subset as
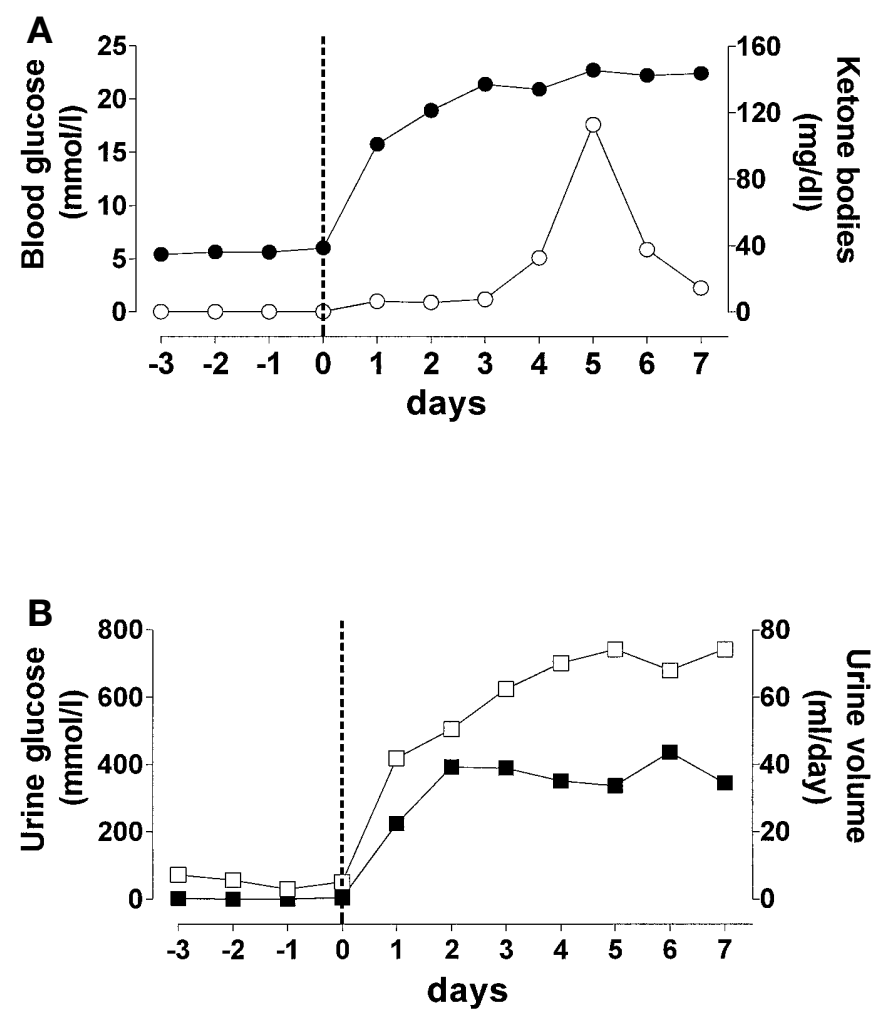

Fig.2A, B. Time course of diabetes development in LEW.1AR1/Ztm-iddm rats kept in metabolic cages during the first week after diabetes manifestation. Day 0 is defined as the last day before diabetes manifestation. Shown are the time courses for hyperglycaemia (blood glucose) (O), glycosuria (urine glucose) ( $\mathbf{\square})$, ketonuria (ketone bodies) $(\bigcirc)$, and polyuria (urine volume) ( $\square$ ). Mean values for 8 rats are given

well as those of the B lymphocytes and the NK cells were not significantly different from those in the control group (Fig. 4).

The pancreatic islets of diabetic rats showed clear signs of insulitis (Fig. 5). An additional immunocytochemical analysis identified the cells of the mononuclear infiltrate as B and T lymphocytes, macrophages and occasional NK cells, which surrounded and permeated all islets of the pancreas. Unaffected islets were not detected. Both $\mathrm{CD}^{+}$and $\mathrm{CD}^{+}$subsets were present.

Electron microscopy identified apoptotic cells as beta cells with the typical signs of margination and condensation of the nuclear chromatin, cell shrinkage and disintegration (Fig. 6A, B). The beta cells undergoing apoptosis were often surrounded by macrophages (Fig. 6B). The apoptotic beta cells contained insulin secretory granules as confirmed through immunogold staining (Fig. 6B, inset). Signs of apoptosis were detected neither in other islet cell types nor in immune cells. Quantitative TUNEL analysis revealed a high number of apoptotic beta cells (Fig. 3B).

In the pancreases of diabetic rats with very high blood glucose concentrations ( $>25 \mathrm{mmol} / \mathrm{l}$ ) so-called 
A
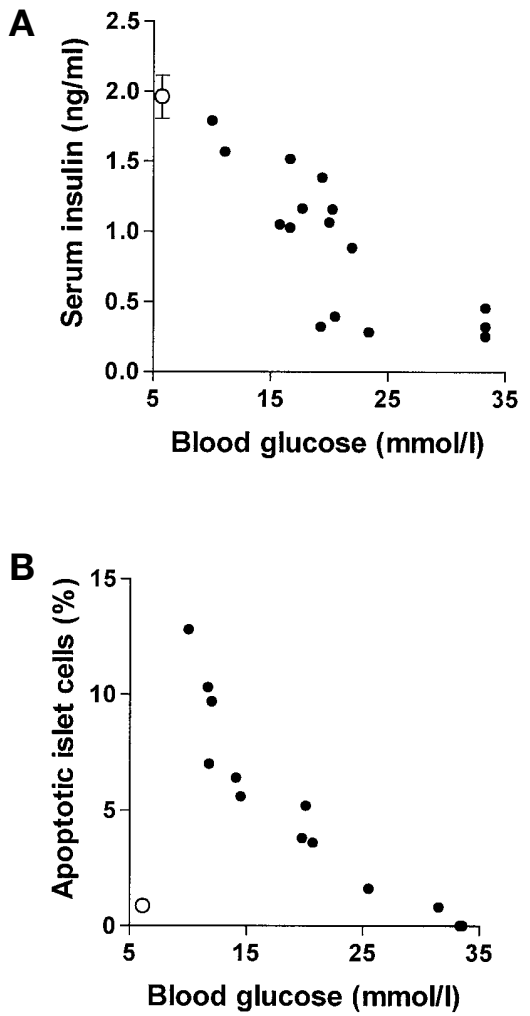

Fig. 3 A, B. Correlation between blood glucose concentration and $\mathbf{A}$ serum insulin concentration and $\mathbf{B}$ the percentage of apoptotic islet cells in the pancreatic islets in diabetic LEW.1AR1/Ztm-iddm rats $(\mathbf{O})$ and control animals $(\bigcirc)$

"end stage islets" were found. These are islets devoid of beta cells and inflammatory cells, composed of $\alpha$ cells with glucagon immunoreactivity and some $\delta$ cells, without an increase in apoptotic cells (Fig.3B).

The pancreases of a group of control LEW.1AR1 rats matched for age and sex and with a non-diabetic genetic background $(n=12)$ as well as of older (120 days) non-diabetic rats from the LEW.1AR1iddm strain $(n=12)$ were also examined microscopically. None of these rats showed signs of pancreatic islet infiltration. Other experiments confirmed that infiltration of pancreatic islets did not appear before rats were 50 days old.

In addition to the pancreas, we studied the liver, kidney, small intestine, spleen, thymus, thyroid gland, adrenal gland, and salivary gland. No morphological changes were observed and in particular, no signs of destructive inflammation, were detected in any of these tissues. In non-diabetic genetic background control LEW.1AR1 rats matched for age and sex $(n=12)$ as well as in older (120 days) non-diabetic rats from the LEW.1AR1-iddm strain $(n=12)$, all of which were free of pancreatic islet infiltrations, no other organs were found to be affected either.

Con A-activated lymphocytes and splenocytes from diabetic LEW.1AR1-iddm rats, which had been adoptively transferred to Poly IC-treated non-diabet-

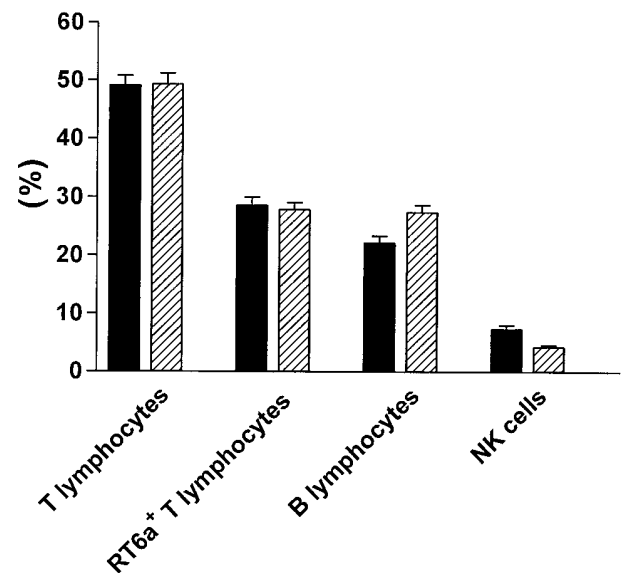

Fig. 4. FACS analysis of the lymphocyte subsets in peripheral blood of diabetic LEW.1AR1/Ztm-iddm rats $(n=26)$ compared with those of non-diabetic control rats $(n=22)$. Mean values \pm SEM are given

ic LEW.1AR1-iddm rats before manifestation of the disease at the age of 29 to 35 days, did not affect the mean age at diabetes manifestation ( $58 \pm 2$ days) but increased the incidence of diabetes to $64 \%$ (9/14 rats) (Table 1). Poly IC treatment alone did not induce diabetes in LEW.1AR1 non-diabetic control rats $(0 / 10$ animals) (Table 1). Transfer of immune cells from diabetic LEW.1AR1-iddm rats to Poly IC-treated non-diabetic control LEW.1AR1 rats caused diabetes in 1 in 10 rats (Table 1 ). Another control experiment confirmed that Con A-activated cells isolated and cultured under identical conditions from healthy LEW.1AR1 control rats did not affect the incidence of diabetes (1/6 rats) in the LEW.1AR1-iddm rat colony.

\section{Discussion}

All rats that spontaneously developed Type I diabetes mellitus were descendants of a single progenitor pair from a congenic LEW.1AR1 rat strain with a defined MHC ( $\left.r 2: R T 1 . A^{a} B / D^{u} C^{u}\right)$ inheriting the disease. The diabetic phenotype is maintained in the inbred strain in a barrier sustained facility (no viral infection, in particular Kilham rat virus negative).

We successfully maintained this colony by breeding non-diabetic female rats with fertile diabetic male offspring which survived for about 4 weeks without insulin replacement after diabetes manifestation. In order to stabilise the colony, we recently started to use insulin-treated diabetic rats for breeding. Using this breeding method, the incidence was in the range of $30 \%$ with a diabetic male partner and double that when both partners were diabetic.

We therefore considered the possibility of autosomal recessive mutation in this strain and, based on this assumption, we denominated background rats as wild type $(+/+)$, diabetic rats as iddm/iddm and 


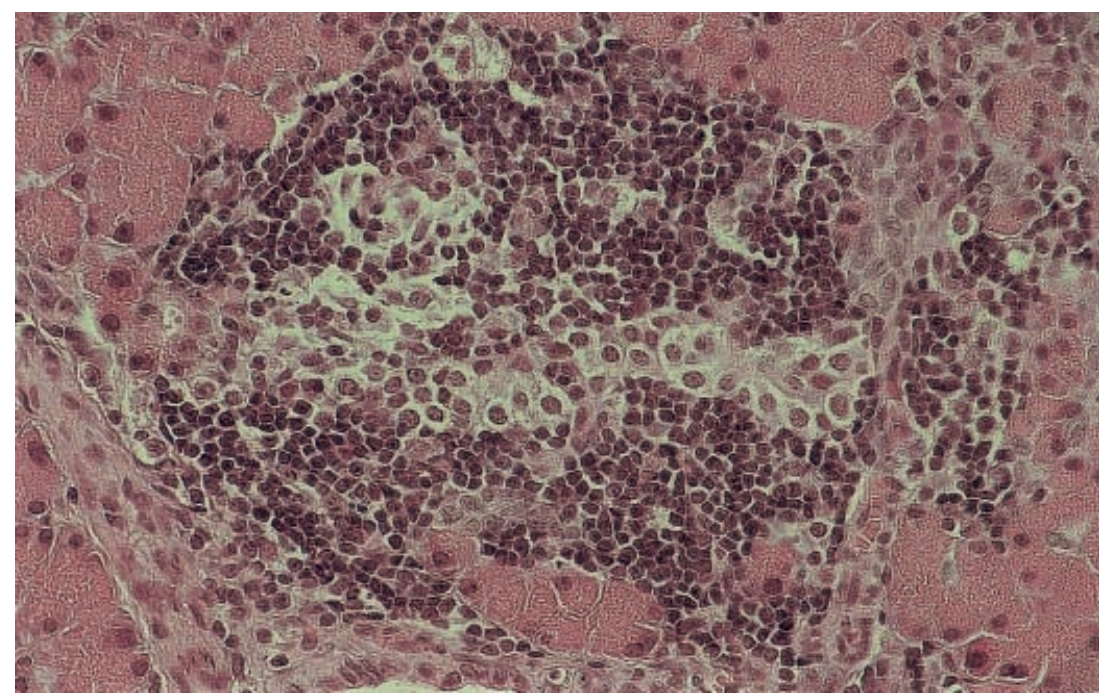

Fig. 5. Pancreatic islet from a diabetic LEW.1AR1/Ztm-iddm rat (blood glucose $18.7 \mathrm{mmol} / \mathrm{l}$ ). The islet shows a mononuclear cellular infiltrate with the highest density at the islet periphery; haematoxylin/eosin $(\times 400)$

non-diabetic rats that produce diabetic offspring as +1 $i d d m$. In spite of our hypothesis of a single mutational event in this colony, we assume that the development of the diabetic syndrome in this strain is the result of a multifactorial trait. This could consist of genes in the LEW background as well as the MHC class II $u$ haplotype. Verification will require a genome wide screening of an informative backcross population.

We refrained from assigning a number to this new $I d d m$ mutation because we cannot differentiate at present from the various susceptibility loci in the rat described by two groups, Iddm3 (RNO18) and Iddm4 (RNO6) [25], or Iddm4 (RNO4), Iddm5 (RNO13) and Iddm6 (RNO3) [26, 27]. As Iddm5 (RNO1) [25] has been defined as a locus conferring resistance to diabetes [25, 27], the mutated locus in LEW.1AR1-iddm could be different. Moreover, lymphopenia, lyp or Iddm1 [28], does not play any part in this new model, irrespective of the fact that the expression of the MHC class II haplotype $u$, designed as $I d d m 2$, is an indispensable requirement for Type I diabetes development [24].

Various genetic factors predisposing to Type I diabetes have been postulated in NOD mice as well as in
BB and LETL rats [3, 5, 8, 29]. Development of the disease typically requires the expression of specific MHC class II haplotypes. As has been shown previously for the BB and LETL rat Type I diabetes models, the expression of the $R T 1^{u}$ haplotype predisposes to diabetes development in a semi-dominant manner $[3,29,30]$. This new Type I diabetic rat also expresses MHC class II $u$ molecules, supporting the contention that this haplotype is crucial for the development of diabetes in rats [24, 31, 32].

The diabetic syndrome in this new Type I diabetes rat model develops very rapidly with an early manifestation at about two months of age. Within one week nearly all beta cells ( $>90 \%$ ) are lost in the affected pancreas. The inability to detect islet cell autoantibodies in this Type I diabetic rat is consistent with the converse observation of high titres of islet cell autoantibodies including GAD in patients with a slow progression to overt diabetes $[33,34]$. The rapid progression of diabetes allowed us to identify the pancreatic beta-cell death in infiltrated islets of this spontaneous diabetes model as apoptosis. Thus apoptotic beta-cell death can be easily studied in vivo in this model. Maximal rates of beta-cell apoptosis observed in the BB rat were lower [35]. In the mouse Type I diabetes model this is possible only after introgressing a beta-cell-specific T cell receptor gene into the NODscid background [36].

The rapid development of the syndrome in this new Type I diabetes model does, however, make it
Table 1. Effects of Poly IC treatment $(7.5 \mu \mathrm{g} / \mathrm{g}$ body weight intraperitoneal for 5 days) and adoptive transfer of lymphocytes and splenocytes $\left(5-7 \cdot 10^{6}\right.$ Con A-activated cells from dia- betic animals) upon induction of diabetes and insulitis in LEW.1AR1 rat strains

\begin{tabular}{llllll}
\hline Rat strain & Number of rats $(n)$ & Poly IC treatment & Adoptive transfer & Insulitis score & Diabetes incidence \\
\hline LEW.1AR1-iddm & 14 & + & + & +++ & $9 / 14$ \\
LEW.1AR1 & 10 & + & - & - & $0 / 10$ \\
LEW.1AR1 & 10 & + & + & ++ & $1 / 10$ \\
\hline
\end{tabular}

Insulitis score: $++=$ moderate cellular infiltration; $+++=$ extensive cellular infiltration 

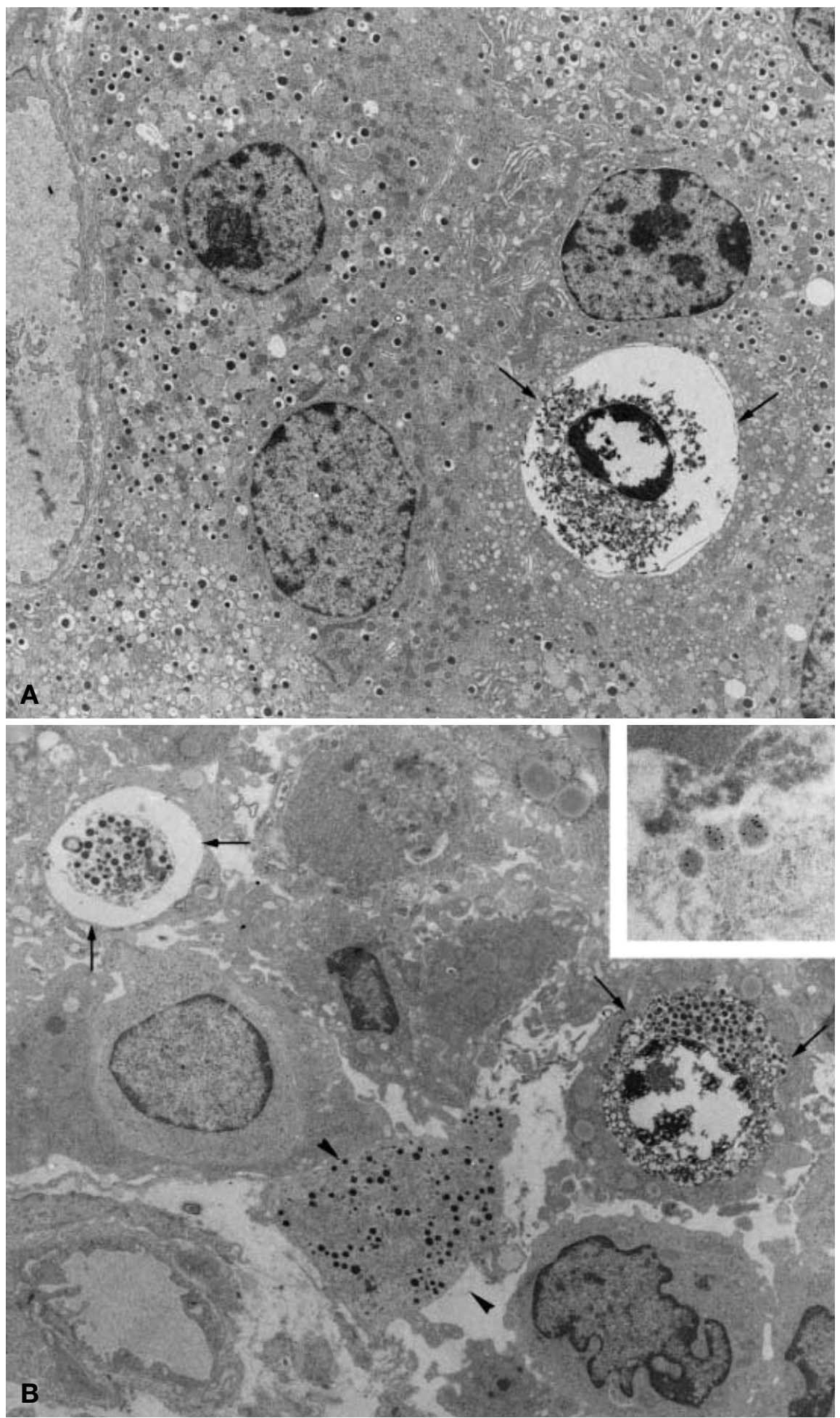

Fig. 6A, B. Pancreatic islet cells from a diabetic LEW.1AR1/ Ztm-iddm rat (blood glucose $10.0 \mathrm{mmol} / \mathrm{l}$ ). Ultrastructurally beta cells show the typical signs of apoptosis with margination and condensation of the nuclear chromatin (arrows). A shows an apoptotic beta cell without infiltration. B shows two apoptotic beta cells surrounded by macrophages; other endocrine cells as shown by the marked $\alpha$ cell remain intact (arrowheads) $(\times 4500)$. Inset: insulin immunostaining of secretory granules in a beta cell undergoing apoptosis $(\times 32000)$ more difficult, compared with other models [37], to monitor the development of the process of autoimmune destruction before clinical manifestation of the disease.

In contrast to the diabetic $\mathrm{BB}$ rat $[11,12]$, genetically determined constitutive lymphopenia with absence of the RT6.1 ${ }^{+} \mathrm{T}$ cell subset does not precede the manifestation of diabetes in this new model. Normal expression of the $\mathrm{T}$ lymphocyte differentiation 
antigen RT6.1 shows that disease development does not seem to be associated with a defect in T cell maturation.

Pronounced insulitis, with the presence of $\mathrm{B}$ and $\mathrm{T}$ lymphocytes, including both $\mathrm{CD}^{+}$and $\mathrm{CD} 8^{+}$subsets, as well as macrophages and NK cells surrounding and permeating all islets are characteristic of an autoimmune process, as shown by the morphological analysis. The autoimmune process leads to the development of Type I diabetes in this congenic LEW rat strain expressing class II MHC molecules of the $R T 1^{u}$ haplotype. Other islet cell types as well as other organs were not affected, showing that the autoimmune process is restricted to the pancreatic beta cell.

Con $\mathrm{A}$ is a polyclonal mitogen which activates all T cells. The fact that Con A-activated cells triple the incidence of diabetes in this LEW.1AR1-iddm rat colony shows that the disease can be transferred adoptively in this strain supporting the concept of a T cell-mediated autoimmunity.

In conclusion, this new Type I diabetes rat strain (LEW.1AR1/Ztm-iddm) develops a spontaneous insulin-dependent autoimmune diabetes as a result of apoptotic beta-cell death and so offers new perspectives for the clarification of the pathogenesis and genetics of Type I diabetes mellitus.

Acknowledgements. H. Weiss is a graduate student in the Graduate Research Training Programme No. 705 funded by the German Research Council (Deutsche Forschungsgemeinschaft). The technical assistance of M. Meyer and S. Eghtessadi is gratefully acknowledged. We thank Dr. W. Richter, Heidelberg, for the antibody determinations. This work has been supported by a grant from the foundation "The Diabetic Child" (Das zuckerkranke Kind). This rat model is also part of a project supported from the Ministry of Education, Science, Research and Technology (BMBF) of the Federal Republic of Germany in the framework of the special funding area "Somatic Gene Therapy".

\section{References}

1. Klöppel G (1985) Experimental insulitis. In: Volk BW, Arquilla ER (ed) The diabetic pancreas. Plenum Press, New York, pp 467-492

2. Rossini AA, Mordes JP, Like AA (1985) Immunology of insulin-dependent diabetes mellitus. Annu Rev Immunol 3: $289-320$

3. Eisenbarth GS, Lafferty KJ (1996) Type I diabetes. Molecular, cellular and clinical immunology. Oxford University Press, New York, Oxford

4. Heward J, Gough SC (1997) Genetic susceptibility to the development of autoimmune disease. Clin Sci (Colch) 93: 479-491

5. Leslie RDG (1997) Molecular pathogenesis of diabetes mellitus. Frontiers Horm Res 22: 1-228

6. Presotto F, Betterle C (1997) Insulin-dependent diabetes mellitus: a constellation of autoimmune diseases. J Pediatr Endocrinol Metab 10: 455-469
7. Lernmark A, Klöppel G, Stenger D et al. (1995) Heterogeneity of islet pathology in two infants with recent onset diabetes mellitus. Virchows Arch 425: 631-640

8. Bach JF (1994) Insulin-dependent diabetes mellitus as an autoimmune disease. Endocr Rev 15: 516-542

9. Bone AJ, Gwilliam DJ (1997) Animal models of insulindependent diabetes. In: Pickup JC, Williams G (ed) Textbook of Diabetes, vol 2. Blackwell Science, Oxford, pp $16.1-16.16$

10. Buschard K (1996) Diabetic animal models. APMIS 104: 609-614

11. Jackson R, Rassi N, Crump T, Haynes B, Eisenbarth GS (1981) The BB diabetic rat. Profound T-cell lymphocytopenia. Diabetes 30: 887-889

12. Greiner DL, Handler ES, Nakano K, Mordes JP, Rossini AA (1986) Absence of the RT-6 T cell subset in diabetesprone BB/W rats. J Immunol 136: 148-151

13. Kikutani H, Makino S (1992) The murine autoimmune diabetes model: NOD and related strains. Adv Immunol 51: 285-322

14. Homo-Delarche F, Boitard C (1996) Autoimmune diabetes: the role of the islets of Langerhans. Immunol Today 17: 456-460

15. Stark O, Günther E, Kohoutova M, Vojcik L (1977) Genetic recombination in the major histocompatibility complex (H-1, Ag-B) of the rat. Immunogenetics 5: 183-187

16. Bender K, Balogh P, Bertrand MF et al. (1994) Genetic characterization of inbred strains of the rat (Rattus norvegicus). J Exp Anim Sci 36: 151-165

17. Hedrich HJ (1990) Genetic monitoring of inbred strains of rat. Gustav Fischer, Stuttgart

18. Kunstyr I (1992) Diagnostic microbiology for laboratory animals. Gustav Fischer, Stuttgart

19. Wiest-Ladenburger U, Hartmann R, Hartmann U, Berling K, Böhm BO, Richter W (1997) Combined analysis and single-step detection of GAD65 and IA2 autoantibodies in IDDM can replace the histochemical islet cell antibody test. Diabetes 46: 565-571

20. Landay AL, Muirhead KA (1989) Procedural guidelines for performing immunophenotyping by flow cytometry. Clin Immunol Immunopathol 52: 48-60

21. Jörns A, Tiedge M, Sickel E, Lenzen S (1996) Loss of GLUT2 glucose transporter expression in pancreatic beta cells from diabetic Chinese hamsters. Virchows Arch 428: 177-185

22. Hsu SM, Raine L, Fanger H (1981) Use of avidin-biotinperoxidase complex (ABC) in immunoperoxidase techniques: a comparison between $\mathrm{ABC}$ and unlabeled antibody (PAP) procedures. J Histochem Cytochem 29: 577-580

23. Wacker HH, Radzun HJ, Parwaresch MR (1985) Ki-M2R, a new specific monoclonal antibody, discriminates tissue macrophages from reticulum cells and monocytes in vivo and in vitro. J Leukoc Biol 38: 509-520

24. Ellerman KE, Like AA (2000) Susceptibility to diabetes is widely distributed in normal class IIu haplotype rats. Diabetologia 43: 890-898

25. Klöting I, Schmidt S, Kovacs P (1998) Mapping of novel genes predisposing or protecting diabetes development in the $\mathrm{BB} / \mathrm{OK}$ rat. Biochem Biophys Res Commun 245: 483-486

26. Martin AM, Maxson MN, Leif J, Mordes JP, Greiner DL, Blankenhorn EP (1999) Diabetes-prone and diabetes-resistant BB rats share a common major diabetes susceptibility locus, iddm4: additional evidence for a "universal autoimmunity locus" on rat chromosome 4. Diabetes 48: 2138-2144 
27. Martin AM, Blankenhorn EP, Maxson MN et al. (1999) Non-major histocompatibility complex-linked diabetes susceptibility loci on chromosomes 4 and 13 in a backcross of the DP-BB/Wor rat to the WF rat. Diabetes 48: 50-58

28. Jacob HJ, Pettersson A, Wilson D, Mao Y, Lernmark A, Lander ES (1992) Genetic dissection of autoimmune type I diabetes in the BB rat. Nat Genet 2: 56-60

29. Kawano K, Hirashima T, Mori S, Saitoh Y, Kurosumi M, Natori T (1991) New inbred strain of Long-Evans Tokushima lean rats with IDDM without lymphopenia. Diabetes 40: $1375-1381$

30. Ellerman KE, Like AA (1995) A major histocompatibility complex class II restriction for BioBreeding/Worcester diabetes-inducing T cells. J Exp Med 182: 923-930

31. Kastern W, Kryspin-Sorensen I (1988) Penetrance and low concordance in monozygotic twins in disease: are they the results of alterations in somatic genomes? Mol Reprod Dev 1: 63-75

32. Temple IK, James RS, Crolla JA et al. (1995) An imprinted gene(s) for diabetes? Nat Genet 9: 110-112
33. Gianani R, Pugliese A, Bonner-Weir S et al. (1992) Prognostically significant heterogeneity of cytoplasmic islet cell antibodies in relatives of patients with type I diabetes. Diabetes 41 : 347-353

34. Harrison LC, Honeyman MC, DeAizpurua HJ et al. (1993) Inverse relation between humoral and cellular immunity to glutamic acid decarboxylase in subjects at risk of insulindependent diabetes. Lancet 341: 1365-1369

35. Lally FJ, Ratcliff H, Bone AJ (2001) Apoptosis and disease progression in the spontaneously diabetic $\mathrm{BB} / \mathrm{S}$ rat. Diabetologia 44: 320-324

36. Kurrer MO, Pakala SV, Hanson HL, Katz JD (1997) Beta cell apoptosis in $\mathrm{T}$ cell-mediated autoimmune diabetes. Proc Natl Acad Sci U S A 94: 213-218

37. Homo-Delarche F (1997) Beta-cell behaviour during the prediabetic stage. Part II. Non-insulin- dependent and insulin-dependent diabetes mellitus. Diabetes Metab 23: 473-505 